\title{
Strength and Durability Studies on Steel Fibre Reinforced Self Compacting Concrete
}

\author{
Dr. M.V. Seshagiri Rao ${ }^{1}$ and Md. Pasha Junead ${ }^{2}$ \\ ${ }^{1}$ Professor, CVR College of Engineering/ Civil Engg. Department, Hyderabad, India. \\ Email: rao_vs_meduri@yahoo.com \\ ${ }^{2}$ PG Scholar, CVR College of Engineering/Civil Engg. Department, Hyderabad, India. \\ Email: m.p.junead786@gmail.com
}

\begin{abstract}
This paper presents the studies on the strength and durability properties of Steel Fibre Reinforced Self Compacting Concrete (SFRSCC) of different grades. Compressive strength and durability performance of Steel Fibre Reinforced Self Compacting Concrete (SFRSCC) using hooked end steel fibres is reported in terms of Chemical Resistance, Initial Absorption Test (ISAT). The rational mix design procedure is used for designing the SCC mixes satisfying the EFNARC (2005) guidelines. In the first phase, the mechanical properties like compressive strength and in the second phase durability properties like Acid-Durability factors, sorptivity were studied for the Plain SCC (SCCP) and Steel Fibre Reinforced SCC (SFRSCC) and comparisons are made. Based on the studies, it is observed that the compressive strengths of the SFRSCC were found to be about $2 \%$ to $10 \%$ more compared to SCCP. The Sorptivity of SFRSCC is found to be reduced, with the addition of steel fibres and increase in the grade of concrete. Acid weight loss factor, the loss of dimension stability, acid strength loss percentage decreases with increase in grade of concrete. With increase in the period of immersion of the concrete in $5 \%$ concentration of acids and sulphates like Na2SO4, HCL, H2SO4, there was a damage of concrete near the corners of the cubes and such disruption in SFRSCC was less than that in SCCP. When compared to the plain SCC, the SFRSCC was found to be more durable against both acids and sulphates.
\end{abstract}

Index Terms: Acid durability factor, Steel Fibres, Acid attack factor, Durability, Self Compacting Concrete, Strength and Sorpitivity.

\section{INTRODUCTION}

Self compacting concrete or self consolidating concrete is defined as a concrete, which has ability to flow under its self weight and to fill every corner of the formwork evenly without any external vibration, while maintaining its homogeneity.

The concept of self compacting concrete is proposed by Professor Hajme Okamura of Japan in 1986 to overcome some of the problems associated with fresh concrete like skill of workers, type and shape of structural section, complexity of reinforcement, segregation, pumpability and compaction. But the prototype was first developed by Professor Ozawa of Japan in 1989.

The BIS has not brought out any standard mix procedure, even though number of agencies and researchers carried out several investigations to establish rational mix design procedure and self compatibility testing methods. The self compacting concrete consists of cement, fine and coarse aggregates, water, mineral and chemical admixtures whose composition is similar to normal concrete. The notable difference between self compacting concrete and normal concrete is that, the self compacting concrete has more fines content, high range water reducing agents and Viscosity Modifying Agent (VMA). Mineral Admixtures are used as extra fine material besides cement, and some cases, they replace cement. The admixtures are used to improve strength and durability properties of concrete.

\section{LITERATURE REVIEW}

Cunha W.V.M.C.F, Barros J.A.O and Sena-Cruz J.M. (2011) [1] presented the work carried out to develop numerical model for the tensile behaviour of SFRSCC. They have assumed SFRSCC as two phase material. The nonlinear material behaviour of self-compacting concrete is given in 3-D smeared crack model. The numerical model showed good correlation with experimental values.

Chandrasekhar M, Seshagiri Rao M V, Janardhana Maganti (2012) et al. [2] Behavior of Fibre Reinforced Self Compacting Concrete and its application as Wall Panels developed by the above authors. In this investigation, Cubes of $100 \mathrm{~mm} \times 100 \mathrm{~mm} \times 100 \mathrm{~mm}$ and cylinders of $150 \mathrm{~mm}$ diameter $\mathrm{x} 300 \mathrm{~mm}$ length were cast for obtaining the compressive strength and stress-strain behaviour of both plain M30 grade SCC and M30 grade SFRSCC separately. The compressive strengths of the FRSCC design mixes are found to have increased by the addition of fibres. However, it is observed in improvement of stress values for the same strains because of addition of fibres.

The stress - strain behaviour of FRSCC and SCC mixes was found to be almost similar. However, it is observed that the addition of fibres has improved the stress values for the same strains. The increase in strain values was observed at peak stresses in all FRSCC mixes and rom the stress-strain behaviour of all types of FRSCC, it is concluded that the ultimate load- carrying capacity and strains at peak stresses are more in SFRSCC and HFRSCC for mixes upto $1.062 \%$ confinement. The hybridization of SCC with glass and steel fibres has shown superior performance amongst all FRSCC mixes. 
W Zhu J Quinn \& P.J.M Bartos (2002) et al. [3] (Aspects of Durability Of Self Compacting Concrete). In the present study, gas permeability, capillary water absorption and chloride diffusivity, which are important indicators for concrete durability performance, of various types of SCC and conventional vibrator reference concrete mixes were assessed and compared.

The SCC mixes have shown significant lower values of sorptivity and coefficient of permeability when compared to the traditional vibrated reference mixes of the same strength grade. The SCC mixes have also shown almost same chloride diffusivity to those of vibrated mixes. However, the chloride diffusivity was found to be very much dependant on the types of powder used in concrete. Both the reference and SCC mixes containing PFA showed much lower values of coefficient of chloride migration than the other mixes. Among the three different SCC mixes, it appeared that the SCC mix containing no additional powder but using the viscosity agent to maintain stability of the fresh mix had the highest permeability, sorptivity and chloride diffusivity, thus less resistant to ingress of aggressive fluids.

S Shrihari and Seshgiri Rao M V (2016) et al. [4] The authors developed Strength and Durability properties of SCC with GBFS and Meta Kaolin. In this development, test results of compressive strength of cubes and cylinders are on lower side with the use of $100 \%$ river sand and the Strength increased where $40 \%$ of GBFS with $10 \%$ of Meta Kaolin were replaced with the river sand.

The physical and chemical properties of GIBFS are suitable for the production of concrete mix. The rapid chloride permeability test and water absorption was conducted, with the use of Meta Kaolin and increasing \% of fly ash with GBFS an improvement in the impermeability of concrete and also the compressive strength and split tensile strength are lower for $0 \%$ replacement. Percentage of water absorption gradually decreases with the use of GIBFS with Meta Kaolin, the replacement of cement by MK leads to decrease in pore space.

N Venkat Rao, M Rajasekhar, Mohd Mujeebuddin Ahmed (2013) The above authors have explained about an Experimental Study on Durability of High Strength Self Compacting Concrete (HSSCC). The test specimens of $10 \mathrm{~cm} X 10 \mathrm{~cm} X 10 \mathrm{~cm}$ cubes were immersed in $5 \%$ of Sodium sulphate solution over a period of time. The performance and properties of concrete that can be affected by sulphate attack were identified. The amount of attack by $\mathrm{H} 2 \mathrm{SO} 4$ is comparatively more when compared with that of HCL and Na2SO4.

The percentage reduction in compressive strength of the specimens with and without immersion in acids (HCL, $\mathrm{H} 2 \mathrm{SO} 4)$ and sulphate (Na2SO4) solutions of $5 \%$ concentration after 28 days was found to be $16.31 \%, 47.07$ $\%$ and $19.86 \%$ respectively. It is noticed that the attack intensity by $\mathrm{H} 2 \mathrm{SO} 4$ is comparatively more than that of $\mathrm{HCL}$ and $\mathrm{Na} 2 \mathrm{SO} 4$. The reduction of strength due to the effect of $\mathrm{H} 2 \mathrm{SO} 4$ on the concrete is more significant.

\section{EXPERIMENTAL Programme}

The experimental programme consisted of casting and testing SCC specimens. The mixes were designed with rational mix design method and several trials were made in producing SCC satisfying the EFNARC specifications (EFNARC, 2005). A total of four grades of concrete were investigated. A total of forty standard cubes of size $150 \mathrm{mmX} 150 \mathrm{mmX} 150 \mathrm{~mm}$ for SCCP, 40 standard cubes for SFRSCC for acid attack, sulphate attack and eight specimens each for SCCP and SFRSCC of size $100 \mathrm{~mm} \times 100 \mathrm{~mm}$ for sorptivity studies, were cast and tested.

\section{Materials ANd Properties}

Cement

Ordinary Portland Cement of 53 grade is used in this investigation. The Cement used was tested as per IS 40311988 and found to be satisfying the specifications of 12269 1987.The specific gravity was 3.2 and fineness was $2.38 \%$.

\section{Coarse Aggregate}

Crushed angular granite of $10 \mathrm{~mm}$ size from a local market was used as coarse aggregate. The specific gravity and fineness modulus were 2.65 and 6.7 respectively.

\section{Fine Aggregate}

River sand was used as fine aggregate. The specific gravity is 2.60 and fineness modulus is 2.79 .

\section{Fly Ash}

Type-II fly ash was used in the present investigation. The properties of fly ash is confirms to I.S. $3812-2002$.

\section{Steel Fibres}

Hooked end steel fibres of $0.4 \mathrm{~mm}$ diameter and Aspect ratio of 30 and $12 \mathrm{~mm}$ length were used.

\section{Super Plasticizer}

Super Plasticizer (Conplast :SP430) having specific gravity 1.22 to 1.225 at $30^{\circ} \mathrm{C}$ and $\mathrm{pH}$ value as $7 \pm 1$, brown colour with no Chloride Content is used.

\section{Viscosity Modifying Agent}

Viscosity modifying agent used is colourless, in liquid form. It is having a Specific of gravity 1.02 $+0.01 @ 25^{\circ} \mathrm{C}$ and $\mathrm{pH}$ value as $8 \pm 1$ with no Chloride Content is used.

\section{Acids and sulphates}

The properties of the constituent acids and sulphate used in the present investigation are LR (laboratory grade) hydrochloric acid $35-38 \%$ with specific gravity 1.18 , LR sulphuric acid $98 \%, 98.07 \mathrm{~g} / \mathrm{mol}$ with specific gravity 1.835 and sodium sulphate with specific gravity of 1.464 , molecular weight $142.036 \mathrm{~g} / \mathrm{mol}$. The concentrations of both acids and sulphate are $5 \%$. 


\section{MiX Proportions}

The Rational mix design methods was used (SV Rao et al., 2010). The details of the mix proportions are shown in Table 1, The fresh properties of the four grades of concrete and the compressive strength of the four grades of concrete were shown.

\section{STRENGTH STUdies}

Before investigating the strength properties of SCC and SFRSCC, the fresh properties of concrete like slump flow T50cm, V-Funnel, L-Box Test were calculated. Later the compressive strength of cubes for 7 days and 28 days were calculated for different grades of SCC and SFRSCC.

\section{DURABILITY STUdIES}

Tests for acid attack and sorptivity were conducted for different grades of SCCP and SFRSCC.

\section{Tests for acid attack on SCCP and SFRSCC}

After 28 days of water curing, each cube was tested for compressive strength and weight. The specimens of different grades viz. M20, M30, M40 and M60 were exposed to $5 \%$ solutions of Sulfuric acid, Hydrochloric acid and Sodium Sulphate for 28 days and 56 days. The response of the specimens to the solutions was evaluated through change in appearance, weight, compressive strength and dimensions of solid diagonals. Before testing, each specimen was removed and brushed and cleaned with water.The resistance of concrete specimens to aggressive environment such as acid attack, durability attack factors such as acid strength loss factor (ASLF), acid attacking factor (AAF), acid weight loss factor (AWLF) and acid durability loss factor (ADLF) (Venkateswara Rao, 2010) are evaluated as per ASTM C 666-1997 (ASTM, 1997).

ASLF gives relative performance of concrete before and after immersion in different acids and Sulphates. The factor also depends on the period of immersion of the specimen in solution. ASLF can be calculated as

Acid strength loss factor $($ ASLF $)=\mathrm{Sr} \times(\mathrm{N} / \mathrm{M})$

Where $\mathrm{Sr}$ is relative strength at $\mathrm{N}$ days (\%), $\mathrm{N}$ is number of days at which the durability factor is required; $M$ is number of days at which the exposure is to be terminated. A lower value of ASLF indicates greater stability towards acid attack.

AAF is meant to determine indirectly the disruption of concrete near the corners of the cube by way of measuring the change in the length of diagonal (referred to as diagonal loss) in a typical concrete cube after immersion in acids and Sulphate for a certain period of time.

A higher value of AAF indicates that the dimensional stability is lower.

AWLF is calculated after immersing the cubes in different solutions for different periods.

A higher value of the AWLF indicates that the weight loss is greater.
In order to have a unified factor describing durability, these factors are combined to derive a factor termed the ADLF.

$$
\mathrm{ADLF}=\mathrm{ASLF} \times \mathrm{AAF} \times \mathrm{AWLF}
$$

\section{Test for Sulphate Attack on SCC and SFRSCC}

Resistance of concrete to the attack has been tested by immersing concrete cubes in the solution of $5 \%$ Sodium Sulphate. The effect of chemical attack has been determined by measuring change of mass into consideration. The test specimens of $100 \mathrm{~mm} \times 100 \mathrm{~mm} \times 100 \mathrm{~mm}$ were immersed in 5 $\%$ of Sodium Sulphate solution for different periods ie. 28 and 56 days and the effect of Sulphate attack on performance properties of concrete are obtained. The resistance of concrete to the Sulphate attack has been estimated by considering changes in their dynamic modulus of elasticity. Even from the visual observation also the intensity of Sulphate attack on disintegration is noticed.

\section{Tests for Sorptivity}

Sorptivity is transport of moisture into unsaturated specimens. Sorptivity is as an important index of concrete durability because the test method used for the determination of Sorptivity reflects the way in which different solutions will penetrate into the concrete. Sorptivity tests were carried out on cubes of size $100 \mathrm{~mm} \times$ $100 \mathrm{~mm} \times 100 \mathrm{~mm}$ on the basis of Hall's method (Hall, 1989).

The Sorptivity Co-efficient (S) was calculated using the following expression

$\mathrm{S}=\mathrm{i} / \mathrm{t} 1 / 2, \mathrm{i}=\Delta \mathrm{W} / \mathrm{Ad}$

Where $\Delta \mathrm{W}$ is the amount of water absorbed $(\mathrm{kg}) ; \mathrm{A}$ is the cross-section of specimen that was in contact with water (m2); $d$ is the density of the medium in which the specimen was dipped ( $\mathrm{d}=1$, as the medium used was water $) ; \mathrm{t}=$ time (min). The unit of $\mathrm{s}$ is $\mathrm{kg} /(\mathrm{m} 2 \mathrm{~min} 1 / 2)$.

The variation of $i$ against $t 1 / 2$ was plotted.

\section{TEST RESULTS AND DISCUSSIONS}

\section{Durability studies}

The durability of different grades SCC and SFRSCC was studied. A total number of 80 cubes were cast and after 56 days of acid environment curing with distilled water. The cubes were tested for compressive strength. From the studies on acid effect on SCC and SFRSCC specimens, it was noted that most of the SFRSCC specimens performed well compared with SCC specimens. To estimate the effects of acid on SCC and SFRSCC, certain factors are determined, as explained in the following paragraphs.

When the specimens were kept in an acid environment, the net loss in strength, physical change in the dimensions of the cube and weight loss were noted. All of these can be considered to derive a unique factor typically depicting the various losses due to acid attack and termed as ADLF (Venkateswara Rao, 2010). The different losses are individually quantified in terms of different factors.

\section{Acid Strength Loss Factor}

The ASLF indicates the variation in the compressive strength of SCC and SFRSCC when kept in different acidic environments, namely $\mathrm{HCl}$ and $\mathrm{H} 2 \mathrm{SO} 4$ at $5 \%$ 
concentrations. Figure 1 shows the variation of ASLF in SCC and SFRSCC for 56 days of immersion in acids. The figure indicates that the SCC and SFRSCC showed more or less similar percentage loss in strength for the different grades of concrete. Furthermore, it is observed that as the strength grade increased there is a slight increase in percentage loss of strength in both SCC and SFRSCC. This justifies the notion that increase in strength may not bring increase in durability, as interpreted from the loss of strength, because, it can be based on performance design rather than the strength-based design of concrete. The ASLF is less for SFRSCC than SCC for $5 \% \mathrm{HCl}$ and the rate of increase of ASLF is greater in sulfuric acid solution.
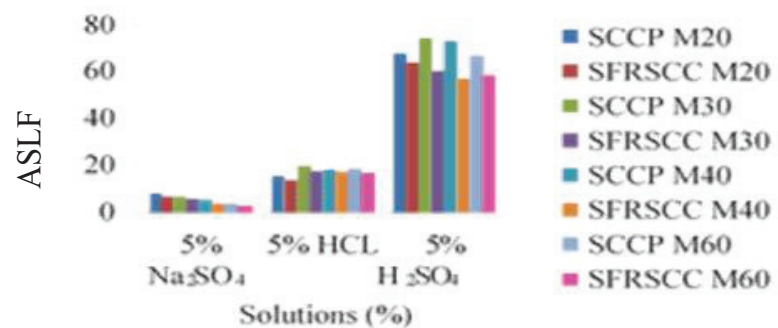

Figure 1. Acid Strength Loss Factors (ASLF) for SCCP and SFRSCC at 56 Days

\section{Acid Attacking Factor}

The AAF gives an idea of the disruption in the geometry of the specimen due to an acidic environment. This is determined by measuring the loss in the diagonals of standard test specimens. The average loss in the diagonals was measured for all the specimens immersed in acid at the end of 28 days and 56 days. The comparison for all the grades of concrete between SCC and SFRSCC revealed that SFRSCC specimens performed better than SCC specimens. Figure 2 shows the variation of AAF in SCC and SFRSCC for 56 days of immersion in acids. This indicates that there is less loss of diagonal (i.e. greater dimensional stability) in SFRSCC mixes than in SCC mixes.

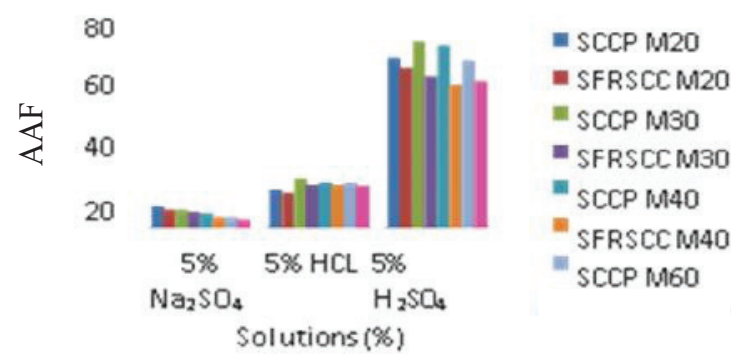

Figure 2. Acid attack factor of SCC and SFRSCC at 56 days of immersion

\section{Acid Weight Loss Factor}

Because of the acidic environment, the $\mathrm{pH}$ of the concrete decreases; at the same time, the cement and the mortar parts breakdown by the acid. This results in decrease in the weight of the specimen. It can be noted in general that the loss is greater with $5 \% \mathrm{H} 2 \mathrm{SO} 4$ than with $\mathrm{HCl}$. Figure 3 shows the variation of AWLF in SCC and SFRSCC for 56 days of immersion in acids.

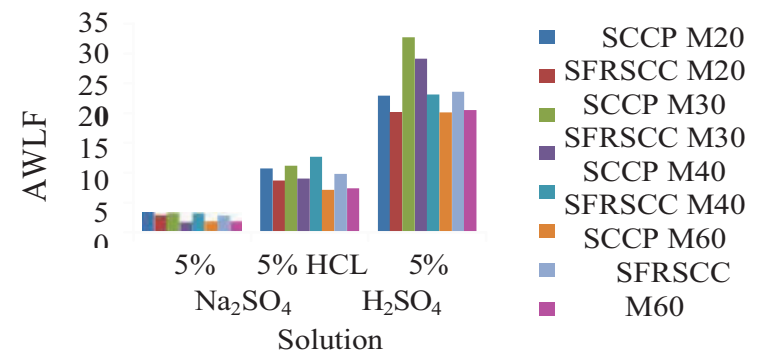

Figure 3. Acid weight loss factors (AWLF) for SCC and SFRSCC at 56 days of immersion

\section{Acid Durability Loss Factor}

As mentioned in previous section losses in strength, weight and geometry are combined to obtain a durability factor termed ADLF. Figure 4 shows the variation of ADLF in SCC and SFRSCC for 56 days of immersion in acids. It can be noted that the losses are greater in SCC specimens than in SFRSCC specimens. Hence, it can be said at this stage that the SFRSCC specimens are more durable compared to SCC. In the present study, four grades of concrete and two types of acids $(\mathrm{HCl}$ and $\mathrm{H} 2 \mathrm{SO} 4)$ and one type of Sulphate with concentration of 5\% were considered. The ADLF values were calculated from the loss factors of ASLF, AAF and AWLF. The average ADLF values are given in Table 2 . Figure 4 shows the variation in average ADLF with acid concentration for both SCC and SFRSCC.

The figure reveals that for $\mathrm{HCL}$ and $\mathrm{Na} 2 \mathrm{SO} 4$ concentrations the SCC and SFRSCC behaved similarly, but as the $\mathrm{H} 2 \mathrm{SO} 4$ concentration increased the $\mathrm{SCC}$ showed higher damage levels than SFRSCC. This indicates that the performance of SFRSCC is better than that of SCC under acidic and Sulphate environmental conditions. It also supports the use of SFRSCC in acidic and Sulphate environments.

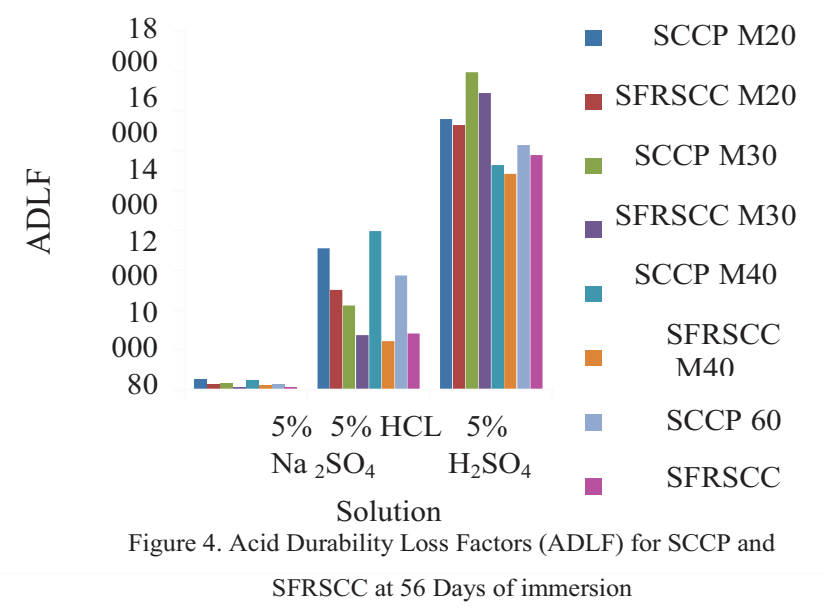

\section{Sorptivity Studies on SCP and SFRSCC}

Sorptivity is the absorption and transmission of water by capillary action (Pereira de Oliveira et al., 2006). Table 4 shows the details of the water absorbed due to capillary action and Sorptivity coefficient for SCC and SFRSCC. Figures 5 \& 6 show the variation of absorbed water per unit area, $\mathrm{i}$ against $\mathrm{t} 1 / 2$ : The cumulative water absorption was less for SFRSCC than for SCC with the increase in time. This is true for all grades of concrete. For the Sorptivity coefficient, asymptotic behaviour was observed for both SCC and SFRSCC mixes. It can be noted from the above tables and figures, that as the grade of concrete increases the water absorption decreases, and the values of water absorption in SCC are much lower than that of SFRSCC. 


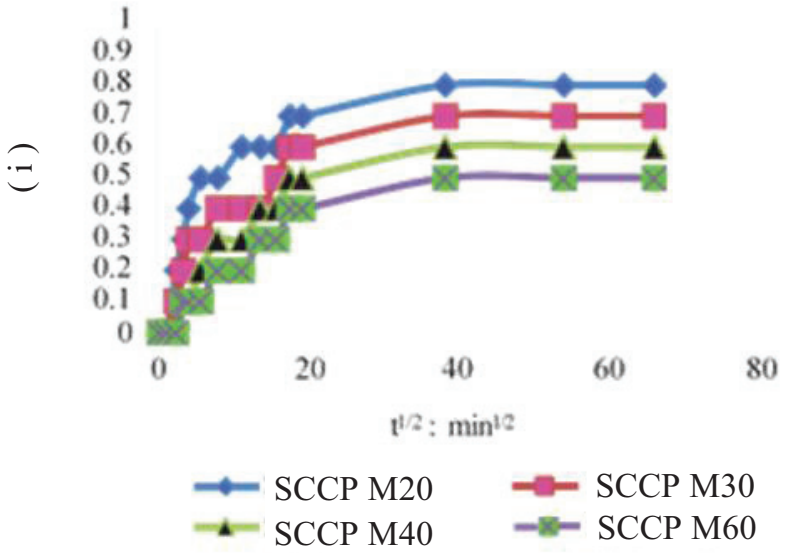

Figure 5. Absorbed water per unit area (i) against time $\left(\mathrm{t}^{1 / 2}\right)$ for SCCP

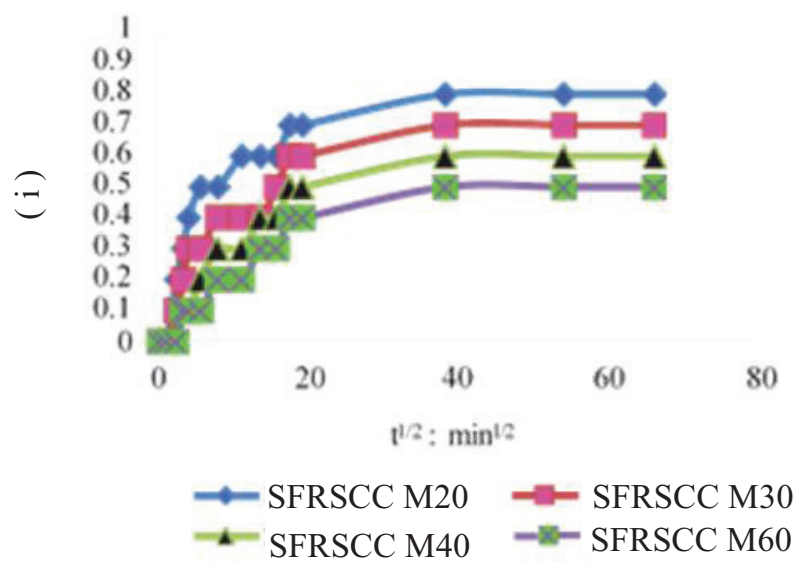

Figure 6. Absorbed water per unit area (i) against time $\left(\mathrm{t}^{1 / 2}\right)$ for SFRSCC

\section{CONCLUSIONS}

The following conclusions are drawn based on the studies on SCC and SFRSCC mixes of different grades

1. Fibre reinforced self-compacting concrete can be produced by incorporating Steel fibres to improve its performance. However, the use of appropriate dosages of super plasticizer and viscosity modifying agent are essential to maintain the fresh properties of selfcompacting concrete.

2. In the case of Steel fibres, a dosage of 31 kilo grams of fibres $/ \mathrm{m}^{3}$ of concrete is found as the optimum dosage by suitably adjusting the dosages of admixtures.

3. With the increase of fibre dosage, the workability decreases. This problem of workability and flow properties of concrete can be overcome by adding superplastizers and VMA.

4. With the increase in the grade of concrete, the Sorptivity of Steel Fibre Reinforced SCC is found to be decreasing.
5. With the increase in period of immersion of the concrete in $5 \%$ concentration of acids like Na2SO4, $\mathrm{HCl}$ and $\mathrm{H} 2 \mathrm{SO} 4$, there was a damage of concrete near the corners of the standard cube .Such disruption in SFRSCC was observed to be less than in SCC, indicating superior durability of SFRSCC.

6. The SFRSCC has shown 3\% more resistance to weight loss, compared to plain SCC.

7. The acid durability loss factor decreases with increase in grade of concrete. When compared to the plain SCC, the SFRSCC was found to be more durable against both acids and sulphates.

8. The acid weight loss factor decreases with increase in the grade of concrete.

9. The AWLF is less in $\mathrm{Na} 2 \mathrm{SO} 4$, when compared to $\mathrm{HCl}$ and $\mathrm{H} 2 \mathrm{SO} 4$.

10. The loss of dimension stability is more in $\mathrm{H} 2 \mathrm{SO} 4$, when compared with HCL and $\mathrm{Na} 2 \mathrm{SO} 4$.

11. Acid strength loss percentage is more in $\mathrm{H} 2 \mathrm{SO} 4$, when compared with HCL and Na2SO4.

12. Compressive strength of SFRSCC is more, when compared with plain SCC

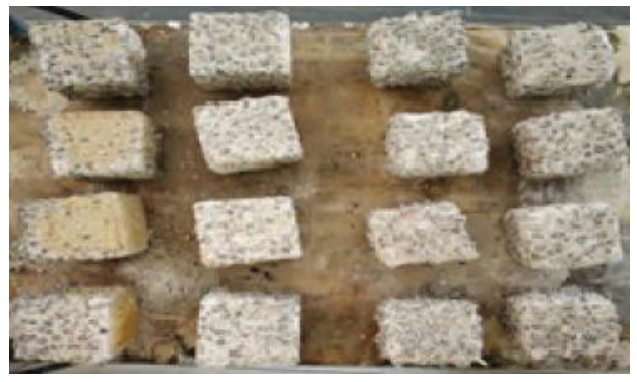

Figure 7

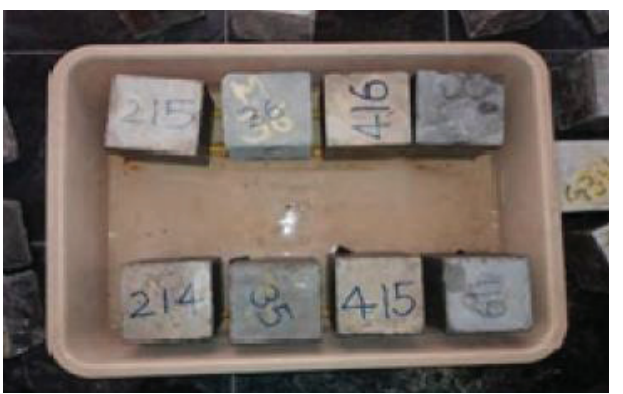

Figure 8

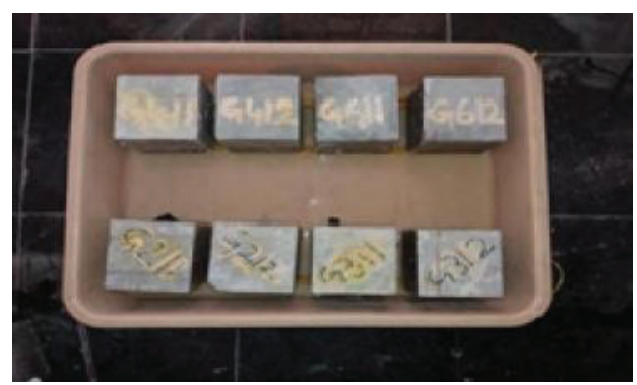

Figure 9

Figure 7,8,9. Sample cubes After Immersion of Specimens in Acids and Sulphate 
TABLE I.

Quantities Per 1 Cum OF SElf COMPACting CONCRETES

\begin{tabular}{|c|c|c|c|c|c|c|c|c|c|}
\hline $\begin{array}{l}\text { Grade of } \\
\text { Concrete }\end{array}$ & $\begin{array}{l}\text { Cement } \\
\left(\mathrm{kg} / \mathrm{m}^{3}\right)\end{array}$ & $\begin{array}{c}\text { Fine } \\
\text { aggregate } \\
\left(\mathrm{kg} / \mathrm{m}^{3}\right)\end{array}$ & $\begin{array}{c}\text { Coarse } \\
\text { Aggregate } \\
\left(\mathrm{kg} / \mathrm{m}^{3}\right)\end{array}$ & $\begin{array}{l}\text { Fly ash } \\
\left(\mathrm{kg} / \mathrm{m}^{3}\right)\end{array}$ & $\begin{array}{c}\text { Water } \\
\left(\mathrm{kg} / \mathrm{m}^{3}\right)\end{array}$ & $\begin{array}{c}\text { SP } \\
\% \\
\text { Bwcf }\end{array}$ & $\begin{array}{c}\text { VMA } \\
\% \\
\text { Bwef }\end{array}$ & $\begin{array}{c}\text { Glass } \\
\text { Fibre } \\
\% \\
\text { Volume }\end{array}$ & Designation \\
\hline \multirow{2}{*}{ M 20} & 260 & 910 & 690 & 310 & 240 & 1 & 0.05 & - & SCCP \\
\hline & 260 & 910 & 690 & 310 & 240 & 1 & 0.05 & 0.024 & SFRSCC \\
\hline \multirow{2}{*}{ M 30} & 355 & 890 & 720 & 350 & 210 & 1.5 & 0.05 & - & SCCP \\
\hline & 355 & 890 & 720 & 350 & 210 & 1.5 & 0.05 & 0.024 & SFRSCC \\
\hline \multirow{2}{*}{ M 40} & 470 & 883 & 720 & 355 & 240 & 1.5 & 0.05 & - & SCCP \\
\hline & 470 & 883 & 720 & 355 & 240 & 1.5 & 0.05 & 0.024 & SFRSCC \\
\hline \multirow{2}{*}{ M 60} & 655 & 860 & 740 & 320 & 260 & 1 & - & - & SCCP \\
\hline & 655 & 860 & 740 & 320 & 260 & 1 & & 0.024 & SFRSCC \\
\hline
\end{tabular}

TABLE II.

HARDENED PROPERTIES OF SCC AND SFRSCC AT 7 AND 28 DAYS

\begin{tabular}{|c|c|c|c|c|}
\hline \multirow[t]{2}{*}{ S.No. } & \multirow[t]{2}{*}{ Grade } & \multirow[t]{2}{*}{ Designation } & \multicolumn{2}{|c|}{$\begin{array}{l}\text { Cube Compressive Strength } \\
\text { ( Mpa ) }\end{array}$} \\
\hline & & & 7 Days & 28 Days \\
\hline 1 & \multirow{2}{*}{20} & SCCP & 17.85 & 26.8 \\
\hline 2 & & SFRSCC & 19.16 & 29.6 \\
\hline 3 & \multirow{2}{*}{30} & SCCP & 24.7 & 38.8 \\
\hline 4 & & SFRSCC & 27.4 & 42.4 \\
\hline 5 & \multirow{2}{*}{40} & SCCP & 33.5 & 51.1 \\
\hline 6 & & SFRSCC & 35.2 & 53.6 \\
\hline 7 & \multirow{2}{*}{60} & SCCP & 41.9 & 66.8 \\
\hline 8 & & SFRSCC & 45.03 & 68.4 \\
\hline
\end{tabular}

TABLE III.

ACID Durability Loss Factors Of Self Compacting CONCRETE MiXes

\begin{tabular}{|c|c|c|c|c|c|c|c|}
\hline \multirow{3}{*}{$\begin{array}{l}\text { Type of } \\
\text { Concrete }\end{array}$} & \multirow{3}{*}{$\begin{array}{l}\text { Grade of } \\
\text { Concrete }\end{array}$} & \multicolumn{6}{|c|}{ Acid Durability Loss Factors } \\
\hline & & \multicolumn{2}{|c|}{$\mathrm{Na}_{2} \mathrm{SO}_{4}$} & \multicolumn{2}{|c|}{ HCL } & \multicolumn{2}{|c|}{$\mathrm{H}_{2} \mathrm{SO}_{4}$} \\
\hline & & 28 Days & 56 Days & 28 Days & 56 Days & 28 Days & 56 Days \\
\hline \multirow{4}{*}{ SCCP } & 20 & 66.01 & 549.36 & 635.45 & 7120.45 & 2521.25 & 13645.2 \\
\hline & 30 & 41.19 & 359.96 & 658.05 & 4239.58 & 2045.83 & 15842.1 \\
\hline & 40 & 68.01 & 495.25 & 1230.55 & 7989.65 & 2539.15 & 11348.0 \\
\hline & 60 & 49.01 & 298.01 & 901.28 & 5770.25 & 3430.54 & 12299.9 \\
\hline \multirow{4}{*}{ SFRSCC } & 20 & 41.01 & 273.11 & 496.12 & 5019.99 & 2472.95 & 13456.2 \\
\hline & 30 & 20.36 & 159.99 & 295.14 & 2759.99 & 2389.51 & 15975.2 \\
\hline & 40 & 34.01 & 219.58 & 359.16 & 2475.69 & 3081.25 & 10910.7 \\
\hline & 60 & 11.97 & 145.35 & 379.99 & 2850.95 & 2580.64 & 10810.2 \\
\hline SCCP & \multirow{2}{*}{$\begin{array}{c}\text { Average } \\
\text { ALDF }\end{array}$} & 55.96 & 427.68 & 856.58 & 6279.66 & 2611.24 & 13310.7 \\
\hline SFRSCC & & 26.29 & 189.96 & 390.52 & 3269.74 & 2567.5 & 12311.8 \\
\hline
\end{tabular}


TABLE IV.

SORPTIVITY FOR SCCP AND SFRSCC

\begin{tabular}{|c|c|c|c|c|c|c|c|c|}
\hline \multirow{2}{*}{$\begin{array}{l}\text { Time } \\
\left(\min ^{1 / 2}\right)\end{array}$} & \multicolumn{8}{|c|}{ Absorption (i) kg/m² } \\
\hline & $\begin{array}{c}\text { SCCP } \\
\text { M20 }\end{array}$ & $\begin{array}{c}\text { SFRSCC } \\
\text { M20 }\end{array}$ & SCCP M30 & $\begin{array}{c}\text { SFRSCC } \\
\text { M30 }\end{array}$ & SCCP M40 & $\begin{array}{c}\text { SFRSCC } \\
\text { M40 }\end{array}$ & SCCP M60 & $\begin{array}{c}\text { SFRSCC } \\
\text { M60 }\end{array}$ \\
\hline 0 & 0 & 0 & 0 & 0 & 0 & 0 & 0 & 0 \\
\hline 1 & 0 & 0.1 & 0 & 0.1 & 0 & 0.1 & 0 & 0 \\
\hline 2.23 & 0.1 & 0.2 & 0 & 0.2 & 0 & 0.1 & 0 & 0.1 \\
\hline 3.16 & 0.2 & 0.3 & 0.1 & 0.2 & 0 & 0.2 & 0 & 0.1 \\
\hline 3.87 & 0.3 & 0.3 & 0.2 & 0.3 & 0.1 & 0.2 & 0.1 & 0.2 \\
\hline 5.47 & 0.4 & 0.4 & 0.2 & 0.3 & 0.1 & 0.3 & 0.1 & 0.2 \\
\hline 7.74 & 0.4 & 0.4 & 0.3 & 0.4 & 0.2 & 0.3 & 0.1 & 0.2 \\
\hline 10.95 & 0.5 & 0.5 & 0.5 & 0.6 & 0.2 & 0.4 & 0.1 & 0.3 \\
\hline 13.41 & 0.5 & 0.6 & 0.3 & 0.5 & 0.3 & 0.4 & 0.2 & 0.3 \\
\hline 15.49 & 0.5 & 0.6 & 0.4 & 0.5 & 0.3 & 0.5 & 0.2 & 0.4 \\
\hline 17.32 & 0.8 & 0.9 & 0.5 & 0.6 & 0.4 & 0.5 & 0.3 & 0.4 \\
\hline 18.97 & 0.6 & 0.7 & 0.5 & 0.6 & 0.4 & 0.5 & 0.3 & 0.4 \\
\hline 37.94 & 0.7 & 0.8 & 0.6 & 0.7 & 0.5 & 0.6 & 0.4 & 0.5 \\
\hline 53.66 & 0.7 & 0.8 & 0.6 & 0.7 & 0.5 & 0.6 & 0.4 & 0.5 \\
\hline 65.72 & 0.7 & 0.8 & 0.6 & 0.7 & 0.5 & 0.6 & 0.4 & 0.5 \\
\hline
\end{tabular}

\section{REFERENCES}

[1] Chandrasekhar M, Seshagiri Rao M V, Janardhana Maganti "Structural Behavour of Steel Fibre Reinforced Self Compacting Concrete Wall Panels" BEFIB2012- $8^{\text {th }}$ RILEM Symposium on Fibre Reinforced Concrete Guimaraes, September 2012.

[2] W V.M.C.F. Cunha, J.A.O. Barros and J.M. Sena- Cruz "An Integrated Approach for Modelling the Tensile Behaviour of Steel Fibre Reinforced Self- compacting Concrete"-Cement and concrete research 41(2011) pp64-76.

[3] V Karthik and G Baskar (2015) "Study on Durability Properties Of Self Compacting Concrete With Copper Slag Partially Replaced For Fine Aggregate" International Journal Of Civil Engineering And Technology (Ijciet)Volume 6, Issue 9, Sep 2015, pp. 20-30, Article ID: IJCIET_06_09_003.

[4] S Venkateswara Rao, M V Seshagiri Rao, D Ramaseshu, P Rathish Kumar "Durability performance of selfcompacting Concrete" Magazine of Concrete ResearchVolume 64 Issue 11 2012.

[5] S Venkateswara Rao, M V Seshagiri Rao, D Ramaseshu, P Rathish Kumar "A Rational Mix Design Procedure for Self Compacting Concrete" 2010.

[6] Ouchi M. and Okamura H. "Effect of Super Plasticizer on Self- Compactability of Fresh Concrete", Journal of the Transportation Research Board, 1997, pp37-40.

[7] Miao Liu "Wider Application of Additions in SelfCompacting Concrete" Ph.D Thesis, University of London, July 2009.

[8] N Venkat Rao, M Rajasekhar, Mohd Mujeebuddin ahmed "An Experimental study on Durability of High strength self compacting concrete" 2013.

[9] S Shrihari and Seshgiri Rao M V "Strength and Durability properties of SCC with GBFS and MetaKaolin" Journal of Chemical and Pharmaceutical Sciences ISSN: 0974-2115, JCHPS Special Issue 2: August 2016.

[10] W Zhu J Quinn \& P.J.M Bartos "Aspects od Durability of Self Compacting Concrete" 2002.

[11] EFNARC, "Specifications and guidelines for self compacting concrete", www.efnarc.org 